\title{
The interpretation of isolated novel nominal compounds
}

\author{
RIET COOLEN, HENK J. VAN JAARSVELD, and ROBERT SCHREUDER \\ University of Nijmegen, Nijmegen, The Netherlands
}

\begin{abstract}
The lexical decision task was used to investigate interpretative processing of isolated novel compounds (noun-noun nominals). On the basis of interpretability ratings, novel compounds were classified as being of either high or low interpretability. In a lexical decision task in which novel compounds functioned as nonwords, a significant interference effect was found for compounds of high interpretability. In a naming task, no differences were found between the two types of novel compounds, but lexicalized compounds resulted in shorter latencies than did novel compounds. Novel compounds were also shown to be interpreted under conditions unfavorable to morphological decomposition, suggesting that the interpretation process is beyond strategic control by the subject. Equal semantic priming effects were obtained for members of established semantic categories and nouns of highly interpretable compounds. Interpretative processes dealing with a limited set of basic semantic relations and analogy with lexicalized compounds are discussed.
\end{abstract}

Theories of language comprehension should not only explain how word meanings are accessed, but also how novel meanings are created on the basis of familiar ones (Gerrig, 1986). Novel compound words provide an excellent testing ground for such theories, because they involve both processes. In normal language use, one often comes across compound words one has never encountered before. Most of these novel compounds ${ }^{1}$ are formed from familiar words for which semantic representations can be accessed. From a psychological point of view, processes underlying the creation of meanings for novel compounds are particularly interesting, because these compounds may be interpreted differently depending on the selection of particular semantic relations between the nouns (Levi, 1978; $\mathrm{Li}, 1971$ ). For instance, a tea lady may denote "a lady one drinks tea with" or "a lady who sells tea" or even "a lady one orders tea from." Despite the multiple ambiguity inherent in novel compounds, intuition and empirical research (e.g., Clark \& Berman, 1987; Coulmas, 1987; Downing, 1977; L. R. Gleitman \& H. Gleitman, 1970 ) indicate that most novel compounds are very easy to interpret.

An obvious explanation of the ease with which novel compounds are interpreted involves the context. Intended interpretations can often be inferred from the linguistic or extralinguistic context (Boase-Beier, 1987; E. V. Clark \& H. H. Clark, 1979; Gerrig, 1989). In “'On Thursday afternoons the baroness enjoyed the company of her tea lady," one will interpret tea lady as "a woman one drinks tea with." The sentence "The baroness ordered a spe-

We would like to thank three anonymous reviewers for their helpful comments on this article. We are also grateful to Eric Schils for his statistical advice. Correspondence should be addressed to Riet Coolen, Interfaculty Research Unit for Language and Speech (IWTS), University of Nijmegen, Wundtlaan 1, 6525 XD Nijmegen, The Netherlands. cial brand from her tea lady" will induce a different interpretation.

Context seems, however, not at all necessary for a fast or "correct" interpretation. Some novel compounds can be assigned a likely meaning on the basis of the semantic aspects of the constituent nouns alone, without any contextual support. Alternative interpretations go unnoticed because one interpretation suggests itself as the most likely one. Consider, for example, novel compounds such as beard louse, curtain piece, or frog song. A beard louse is very likely to be "a louse in a beard"; a curtain piece is almost certainly "a piece of cloth for a curtain"; a frog song is most probably "a song sung by frogs." The interpretation preferred for a compound in isolation may even be in conflict with an interpretation suggested by the context (Boase-Beier, 1987). In the sentence "The biologist wrote a dissertation about the beard louse," one is more likely to interpret beard louse as a special subspecies of lice rather than "a louse in a beard." These general observations suggest that the interpretation of novel compounds is determined jointly by the semantic aspects of the constituent nouns and some larger context. The relative contribution of each to the interpretation process will depend on the interpretability of the compound on its own and the amount of relevant contextual information.

For the investigation of interpretation processes for novel compounds, these observations suggest that novel compounds should be studied both in isolation and in context. By studying compounds in isolation, one may be able to determine the contribution of the semantic representations of the constituent nouns to the interpretation process. Moreover, empirical evidence about interpretation processes in isolation is essential for specifying the role of context in more detail. The role of the context will not be properly understood when the role of the semantic representations in the compound itself is left undetermined 
(see Forster, 1976, for a similar argument dealing with the role of context in lexical access).

Semantic processing of isolated novel compounds may be investigated by a variety of tasks. Until very recently, untimed off-line tasks, such as paraphrasing, attribute generation or typicality judgments have been used (e.g., Downing, 1977; L. R. Gleitman \& H. Gleitman, 1970; Hampton, 1988). One of the disadvantages of off-line semantic tasks is the appeal to aspects of verbal ability or creativity that are distributed unequally across subjects (Geer, H. Gleitman, \& L. Gleitman, 1972). More importantly, these tasks may give rise to rather elaborated processing, including imaging situations or scenarios in which the compound would be pragmatically meaningful (see Barsalou, 1983). Turning to tasks that involve online measurement, one obvious option is a speeded semantic classification task (Murphy, 1990) in which subjects are required to classify compounds for meaningfulness. Since deciding upon meaningfulness may be a very global judgment, one cannot be sure that decision times only reflect interpretation processes based on the meanings of the nouns. Considerations that are contingent on the interpretation of the compound (e.g., judging the plausibility of the object that is described by the compound) may also have an effect on decision processes.

More accurate assessment of interpretation processes based on the semantic representations of only the nouns may be achieved by using tasks that do not require interpretation or tasks in which interpretation would be even disadvantageous. In such tasks, indications would be obtained for an automatic interpretation of compounds, "triggered" simply by juxtaposing (the semantic representations of) constituent nouns. Thus, nonsemantic tasks would provide sensitive indications for the extent and ease with which semantic representations are integrated, avoiding additional semantic and/or pragmatic considerations.

The lexical decision task would seem to be a task that may fulfill these requirements. The performance of the lexical decision task does not require semantic processing. Decisions may be based solely on the availability of orthographic representations. Semantic aspects of stimuli have been shown to affect lexical decision times (James, 1975; Jastrzembski, 1981; Whaley, 1978). More importantly, the lexical decision task appears to be very sensitive to postlexical semantic integration effects (Forster, 1979). Several studies have reported sizable effects of semantic variables using a lexical decision task, but much smaller effects or even a failure to replicate these effects with a naming task (Chumbley \& Balota, 1984; Lupker, 1984; Seidenberg, Waters, Sanders, \& Langer, 1984). Clearly, the interpretation of novel compounds is postlexical because it requires the prior activation of the meaning of the constituent nouns. In view of these characteristics, the lexical decision task may therefore be quite promising for uncovering differences in interpretative processing of novel compounds. The main purpose of our research has been to validate the lexical decision task as a means for investigating interpretative processing of novel compounds.

In the experiments reported below, we used differences in interpretability between novel compounds as independent measures. Isolated novel compounds may be scaled for interpretability. Compounds at both ends of the interpretability scale served as stimuli in our experiments. We will designate items at the upper end of the scale as highinterpretable $(\mathrm{HI})$ compounds and items at the lower end as low-interpretable (LI) compounds.

In Experiment 1, we used a lexical decision task in which lexicalized compounds served as words and $\mathrm{HI}$ and LI compounds served as nonwords. It may be assumed that for the HI and LI compounds the semantic representations of the constituent nouns will become available. If relations are being established between these representations, subsequent decision processes may be affected. For the HI compounds, the meaning of the constituent nouns will be integrated into a meaningful unit. For these items, a conflict arises between the meaningfulness of the compound (which suggests a "yes"' response) and the nonavailability of an orthographic representation (which suggests a "no" response). The resolution of this conflict will cause latencies and number of errors to increase, relative to the $\mathrm{LI}$ compounds for which both meaninglessness and nonavailability of orthographic representations suggest a "no" response.

In Experiment 2, we used a naming task for the same stimulus materials as in Experiment 1 . This naming experiment provides evidence that differences between $\mathrm{HI}$ and LI compounds cannot be attributed to uncontrolled lexical variables. It also supports the interpretation of the results of Experiment 1 as due to postlexical integration effects. Experiment 3 was conducted to determine whether or not interpretative processing was under strategic control of the subject by varying the composition of the stimulus materials. The purpose of Experiment 4 was to provide evidence about the extent of the interpretation process in a lexical decision task. In the General Discussion section, we offer some suggestions with respect to underlying differences between $\mathrm{HI}$ and $\mathrm{LI}$ compounds and we relate our results to recent theorizing about conceptual combinations.

\section{EXPERIMENT 1}

\section{Method \\ Rating studies. A set of 200 novel compounds was especially constructed for the purpose of Experiment 1. All novel compounds consisted of two simple nouns, each of which occurred separately in Dutch. One half of the noun-noun compounds was intuitively felt to be easy to interpret (for example grieptijd [flu season] or paleiskelner [palace waiter]) and the other half of the compounds was felt to be difficult to interpret (for example boomzonde Itree sin] or haakverkeer [hook traffic]). Each constituent noun occurred only once in the stimulus materials. To avoid segmentation}


problems, all novel compounds were constructed in such a way that boundaries between two constituent nouns were unambiguous. Compounds such as plaatstaal, for instance, were not included because they can be segmented in different ways (e.g., plaat + staal [sheet of steel] or plaats + taal [local language]). ${ }^{2}$

All 200 novel compounds were pretested for interpretability in two separate rating studies. In Rating Study 1, the subjects were asked how easy it was to come up with a meaning for the compound. Thirty subjects, all students at Nijmegen University, participated in Rating Study 1. Each subject was given a booklet containing the novel compounds and was instructed to rate each compound on a 7-point scale $(1=$ very difficult to interpret; $7=$ very easy to interpret). Order of presentation of the compounds was random for each subject, and no time pressure was applied.

In Rating Study 2, 200 lexicalized compounds were added to the stimulus set. ${ }^{3}$ Interpretability ratings may be affected by the composition of the set of stimulus materials. In particular, reliable differences in interpretability for novel compounds may disappear when lexicalized compounds are included in the stimulus materials, due to changing criteria for meaningfulness. A compound was considered lexicalized if it was listed in Van Dale's (1984) Groot Woordenboek der Nederlandse Taal, which is the most complete dictionary on the Dutch language and the Dutch CELEX database, a computerized lexical database based on $\mathbf{4 2}$ million tokens (Burnage, 1990). Novel compounds, of course, did not appear in either list. Instructions and procedure were exactly the same as in Rating Study 1 . Another group of $\mathbf{3 0}$ students performed Rating Study 2, and none of them had participated in Rating Study 1.

In Rating Study 1, mean interpretability scores were significantly higher for compounds that were considered to be easy to interpret (5.9) than for compounds that were difficult to interpret (3.1) in both the subject and item analyses $\left[F_{s}(1,29)=841.00, M S_{\mathrm{e}}=.2\right.$, $\left.p<.001 ; F_{\mathrm{i}}(1,198)=400.49, M S_{\mathrm{e}}=1, p<.001\right]$. In Rating Study 2 , the subjects found lexicalized compounds $(6.2)$ to be easier to interpret than were novel compounds $(3.9)\left[F_{s}(1,29)=444.06\right.$, $\left.M S_{\mathrm{e}}=.2, p<.001 ; F_{\mathrm{i}}(1,398)=288.44, M S_{\mathrm{e}}=2, p<.001\right]$. The difference between both groups of novel compounds was also highly significant $\left[F_{\mathrm{s}}(1,29)=272.94, M S_{\mathrm{e}}=.4, p<.001\right.$; $\left.F_{\mathrm{i}}(1,198)=406.83, M S_{\mathrm{e}}=.9, p<.001\right]$. Mean scores were 5.2 for novel compounds that were easy to interpret and 2.5 for novel compounds that were difficult to interpret.

Rating scores for the novel compounds in Rating Studies 1 and 2 were analyzed simultaneously to assess the effect of composition of the set of stimulus materials on interpretability judgments. A significant effect for rating study indicated that the inclusion of lexicalized compounds resulted in generally lower rating scores for the novel compounds $\left[F_{\mathrm{s}}(1,58)=11.34, M S_{\mathrm{e}}=1, p<.01\right.$; $\left.F_{\mathrm{i}}(1,198)=186.47, M S_{\mathrm{e}}=.2, p<.001\right]$. However, this general decrease did not affect the distinction between novel compounds that were easy or difficult to interpret $\left[F_{\mathrm{s}}(1,58)=859.49, M S_{\mathrm{c}}\right.$ $\left.=.3, p<.001 ; F_{\mathrm{i}}(1,198)=458.58, M S_{\mathrm{e}}=2, p<.001\right]$. The interaction between rating study and interpretability of novel compounds was not significant. Mean interpretability scores for novel compounds occurring in both studies were highly correlated $(r=.94, p<.001)$.

To determine the reliability of the ratings of the novel compounds, split-half analyses of the data for both rating studies were carried out. The 30 subjects of each study were randomly divided into two subgroups of 15 subjects each. The split-half reliabilities were .94 and .96 for Rating Studies 1 and 2, respectively $(p<.001$, for both $r s$ ). In both studies, missing data amounted to less than $0.1 \%$ of the total data.

The results of these rating studies clearly show that novel compounds can be distinguished consistently and reliably with respect to interpretability. In both rating studies, significant differences between the two groups of novel compounds were found. The inclu- sion of lexicalized compounds led to a general decrease in mean rating scores, but did not affect distinctions in interpretability.

For the lexical decision experiment, 60 lexicalized and 60 novel compounds were selected from the larger set used in the rating studies. Lexicalized and novel compounds were matched for mean number of letters, as were the HI and LI compounds. All selected novel and lexicalized compounds are listed in the Appendix. Of the 60 novel compounds, 30 were $\mathrm{HI}$ compounds and 30 were $\mathrm{LI}$ compounds. Interpretability scores for individual $\mathrm{HI}$ compounds in Rating Study 1 were at least 6.0. Mean interpretability scores for all selected $\mathrm{HI}$ compounds were $6.6(S D=.49)$ in Rating Study 1 and $5.8(S D=.50)$ in Rating Study 2. Selected LI compounds had interpretability scores ranging between 1.0 and 3.5 in Rating Study 1. Mean interpretability scores were $2.1(S D=.55)$ in Rating Study 1 and 1.7 ( $S D=.57)$ in Rating Study 2.

Procedure and Subjects. Stimuli appeared in lowercase letters on a video display unit connected to an Olivetti M-24 personal computer. The subjects were seated in a room with subdued lighting. Each trial started with the display of an asterisk $\left({ }^{*}\right)$ in the middle of the screen, which remained visible for $500 \mathrm{msec}$. Subsequently, the stimulus item was displayed for $4,000 \mathrm{msec}$ or until a response was made. The intertrial interval was $2,000 \mathrm{msec}$. The subjects were instructed as follows: "In this experiment, you will see a number of compounds which are all composed of two nouns. Some of them form an existing Dutch compound (for example, fietsbel [bicycle bell]); others, however, do not figure in Van Dale and in fact don't belong to the Dutch language (for example, breinklus [brain job]). After you have read the compound, your task is to push the ja (yes) button when the compound as a whole is an existing Dutch word or to push the nee (no) button if the compound as a whole is not an existing Dutch word. It is important that you respond as quickly as possible, but you should also make as few errors as possible. Before the actual experiment starts a number of practice trials will appear on the screen." The instruction did not state that there would be $\mathrm{HI}$ compounds included in the materials.

Prior to the presentation of the 120 test items, the subjects were presented with 48 practice items. Experimental sessions lasted about $20 \mathrm{~min}$. Twenty-five paid subjects, drawn from the subject pool of the IWTS, participated in Experiment 1.

\section{Results}

Data from 3 subjects, whose error percentages exceeded a preset criterion of $15 \%$ for the lexicalized compounds, were discarded. In this and the subsequent experiments, the effects of very long or short latencies were minimized by establishing a cutoff point equal to 2.0 standard deviation units from subject and item means. On the basis of the results of the rating studies, we regarded classifications of compounds that differed from the experimental classification as "errors." Any outlying values were considered errors. Reaction times for incorrect responses were not included in the analyses. Since the HI/LI distinction reflects the extremes of a continuum of interpretability along which novel compounds can be scaled, correlations between reaction times and interpretability ratings are also reported.

The difference in mean latencies for the lexicalized compounds (742 $\mathrm{msec})$ and novel compounds $(889 \mathrm{msec}$ ) was highly significant $\left[F_{\mathrm{s}}(1,21)=63.81, M S_{\mathrm{e}}=3,905, p<\right.$ $\left..001 ; F_{\mathrm{i}}(1,118)=99.79, M S_{\mathrm{e}}=6,560, p<.001\right]$. Differences in error percentages for words $(6.1 \%)$ and nonwords $(12.5 \%)$ were also significant $\left[F_{\mathrm{s}}(1,21)=\right.$ 
Table 1

Mean Latencies (in Milliseconds) and Percentages of Errors for All Compounds in Experiment 1 and for the Subset of the Novel Compounds with Less than 25\% Errors

\begin{tabular}{lcc} 
& \multicolumn{2}{c}{ Stimuli } \\
\cline { 2 - 3 } & All Items & Subset \\
\hline Latencies & Lexicalized Compounds & \\
Error Percentages & 6.1 & \\
& HI Compounds & \\
Latencies & 926 & 911 \\
Error Percentages & 22.4 & 14.6 \\
& LI Compounds & \\
Latencies & 854 & 848 \\
Error Percentages & 2.8 & 6.9 \\
\hline
\end{tabular}

$14.35, M S_{\mathrm{e}}=11, p<.01 ; F_{\mathrm{i}}(1,118)=8.99, M S_{\mathrm{e}}=7$, $p<.01]$. Mean latencies and percentages of errors for all stimulus categories are presented in Table 1.

For the novel compounds, interpretability had a significant effect on latencies $\left[F_{\mathrm{s}}(1,21)=46.30, M S_{\mathrm{e}}=1,277\right.$, $\left.p<.001 ; F_{\mathrm{i}}(1,58)=14.15, M S_{\mathrm{e}}=5,443, p<.001\right]$. As expected, more errors were made for $\mathrm{HI}$ compounds than for LI compounds $\left[F_{\mathrm{s}}(1,21)=49.80, M S_{\mathrm{e}}=8, p<\right.$ $\left..001 ; F_{\mathrm{i}}(1,58)=61.62, M S_{\mathrm{e}}=5, p<.001\right]$.

The correlation between mean decision times and mean rating scores was .44 for both ratings $(p<.001)$.

\section{Discussion}

The differences in decision latencies and error percentages between $\mathrm{HI}$ and $\mathrm{LI}$ compounds indicate that the novel compounds were interpreted. Interpretability of the novel compounds interferes with the lexical decision. For HI compounds, a conflict arises between the nonavailability of an orthographic representation and the meaningfulness of the compound. The resolution of this conflict will cause latencies and number of errors to increase, relative to the LI compounds for which both meaninglessness and nonavailability of orthographic representations suggest a "no" response.

Interpretation of novel compounds is not required by the task and appears to be even disadvantageous because it results in significantly longer latencies for the HI compounds. Therefore, interpretation of novel compounds in a lexical decision task are supposed to be performed automatically (cf. Seidenberg et al., 1984).

It may be objected that the interference effect observed for the HI compounds might also be due to subjects' greater uncertainty about the lexical status of these compounds. The distinction between lexicalized compounds and HI compounds may be a difficult one to make (after all, HI compounds could well be words). To investigate this alternative account, we selected $19 \mathrm{HI}$ compounds for which there is little doubt about their lexical status, as indicated by an error percentage of less than $25 \%$. This subset was compared with a subset of 19 equally long LI compounds. If the interference effect for the HI compounds is due to uncertainty about the lexical status of HI compounds, the interference effect should be substantially smaller for this subset.

In Table 1, it can be seen that the mean latency for the subset of $19 \mathrm{HI}$ compounds ( $911 \mathrm{msec})$ was longer than for the subset of $19 \mathrm{LI}$ compounds [848 $\mathrm{msec} ; F_{\mathrm{s}}(1,21)=$ $25.63, M S_{\mathrm{e}}=2,356, p<.001 ; F_{\mathrm{i}}(1,36)=8.31, M S_{\mathrm{e}}=$ $4,560, p<.01$ ]. Also, more errors were made for the HI compounds than for the LI compounds $\left[F_{\mathrm{s}}(1,21)=\right.$ $15.71, M S_{\mathrm{e}}=3, p<.005 ; F_{\mathrm{i}}(1,36)=36.94, M S_{\mathrm{e}}=$ $2, p<.001]$. Although the interference effect for the subset was slightly smaller than for the whole set, the decrease was not significant $(F<1)$. Thus, leaving out response latencies for those HI items that yielded most errors did not lead to a reduction of the interference effect. This result makes it rather unlikely that uncertainty about lexical status may explain the observed differences between $\mathrm{HI}$ and LI compounds. However, there are other alternative explanations for the interference effect that need to be ruled out.

\section{EXPERIMENT 2}

In Experiment 2, subjects performed a naming task for the stimulus materials used in Experiment 1. By means of the naming task, we wanted to rule out two alternative explanations of the differences between $\mathrm{HI}$ and LI compounds found in Experiment 1. One alternative account has to do with uncontrolled lexical variables of the nouns making up the $\mathrm{HI}$ and $\mathrm{LI}$ compounds. The comparison between $\mathrm{HI}$ and $\mathrm{LI}$ compounds involved different constituent nouns and certain aspects of these nouns, such as frequency or orthographic regularity, may have caused the observed difference between HI and LI compounds. In addition, unsuspected nonsemantic differences between the two types of compounds like ease of segmentation into constituent nouns may (partly) explain the difference.

The second alternative account has to do with differences in semantic relatedness between the nouns in the two types of novel compounds. We have argued above that differences in interpretability arise postlexically, because integration depends on prior activation of the meanings of the nouns involved. However, semantic relations may exist between constituent nouns that might give rise to prelexical priming effects (Lupker, 1984; Neely, 1991; Schreuder, Flores d'Arcais, \& Glazenborg, 1984; Seidenberg et al., 1984). These semantic relations may be assumed to be stronger for the HI compounds; a priming effect between constituent nouns may be the cause of the interference effect for these items.

Both alternative accounts suggest that significant differences between $\mathrm{HI}$ and $\mathrm{LI}$ compounds will also be found in the naming task. Nonsignificant differences between the two types of novel compounds will make it rather unlikely that unsuspected nonsemantic aspects of the compounds or of the constituent nouns have caused the la- 
tency difference in the lexical decision task. They will also support a postlexical interpretation of the interpretability differences.

Lexicalized compounds were included in the stimulus materials to obtain insight in specific access procedures that might be adopted for the pronunciation of long compound words. Both constituent nouns may be accessed before pronunciation starts, but a viable alternative processing strategy consists in initial access of the first noun only. Pronunciation of this noun may start before an orthographic or a phonological representation of the whole stimulus has been constructed (Henderson, 1982). Access of the second noun may occur subsequently, possibly in parallel with the pronunciation of the first noun.

No differences in naming latencies for lexicalized and novel compounds are to be expected when the pronunciation of compound words is based on the initial access of the first noun only. For both categories, pronunciation may start as soon as the first noun has been accessed (cf. Taft, 1985; Taft \& Forster 1976). Shorter naming latencies for lexicalized compounds, however, will provide convincing evidence that somehow the whole stimulus was processed before pronunciation was initiated.

\section{Method}

Stimulus materials. The same 60 novel and 60 lexicalized compounds as in Experiment 1 were used. To match lexicalized compounds with novel compounds for initial phonemes, eight lexicalized compounds were added to the materials. Within the whole set of 128 compounds, there were three subsets of matched stimuli. One subset consisted of 32 lexicalized compounds, the second subset of $16 \mathrm{HI}$ compounds, and the third of $16 \mathrm{LI}$ compounds. Matching involved the first phoneme, mean word length, mean number of syllables, and absolute frequency of the first constituent noun (Uit den Boogaart, 1975; Van Jaarsveld \& Rattink, 1988).

Procedure and Subjects. The subjects were instructed to name the stimuli as quickly as possible. Responses triggered a voice key. Latencies were measured from the onset of the stimulus until the onset of the vocal response. Reading errors, hesitations, and untimely triggerings of the voice key were registered as errors by the experimenter. All other experimental procedures were the same as in Experiment 1.

Twenty subjects, drawn from the subject pool of the IWTS, participated in Experiment 2. None of the subjects had participated in Experiment 1.

\section{Results}

Two separate analyses of the data were carried out: one analysis for all items that were also used in Experiment 1, and a second one for matched subsets of compounds. Mean latencies and error percentages for these different sets of data are presented in Table 2.

The analysis for items that also occurred in Experiment 1 showed that naming latencies for lexicalized compounds $(533 \mathrm{msec})$ were shorter than for novel compounds [565 msec; $F_{\mathrm{s}}(1,19)=41.88, M S_{\mathrm{e}}=242, p<$ $\left..001 ; F_{\mathrm{i}}(1,118)=36.86, M S_{\mathrm{e}}=799, p<.001\right]$. Mean latencies for $\mathrm{HI}$ compounds ( $563 \mathrm{msec}$ ) and LI compounds $(566 \mathrm{msec})$ were not significantly different $(F<1)$. The correlation between mean latencies for novel compounds

\section{Table 2}

Mean Latencies (in Milliseconds) and Percentages of Errors for All Compounds in Experiment 2, Subsets of Compounds Matched for Initial Phonemes, and Subsets used in the Control Experiment

\begin{tabular}{|c|c|c|c|}
\hline & \multicolumn{3}{|c|}{ Stimuli } \\
\hline & $\begin{array}{c}\text { All } \\
\text { Items }\end{array}$ & $\begin{array}{c}\text { Matched } \\
\text { Phonemes }\end{array}$ & $\begin{array}{l}\text { Control } \\
\text { Subset }\end{array}$ \\
\hline \multicolumn{4}{|c|}{ Lexicalized Compounds } \\
\hline Latencies & 533 & 541 & 498 \\
\hline Error Percentages & 0.5 & 0.9 & 1.2 \\
\hline \multicolumn{4}{|c|}{ HI Compounds } \\
\hline Latencies & 563 & 573 & 501 \\
\hline Error Percentages & 3.3 & 3.1 & 2.2 \\
\hline \multicolumn{4}{|c|}{ LI Compounds } \\
\hline Latencies & 566 & 575 & 497 \\
\hline Error Percentages & 6.8 & 6.9 & 0.5 \\
\hline
\end{tabular}

and their mean rating scores (see Experiment 1) was -.08 for both rating versions (both $p s>.5$ ).

The analysis of the errors for the same items showed a significant effect of lexicality $\left[F_{\mathrm{s}}(1,19)=30.65, M S_{\mathrm{e}}=\right.$ $\left.2, p<.001 ; F_{\mathrm{i}}(1,118)=26.95, M S_{\mathrm{e}}=1, p<.001\right]$. More errors were made for novel compounds than for lexicalized compounds. Also, more errors were made for $\mathrm{LI}$ compounds than for $\mathrm{HI}$ compounds $\left[F_{s}(1,19)=7.62\right.$, $\left.M S_{\mathrm{e}}=1, p<.05 ; F_{\mathrm{i}}(1,58)=4.46, M S_{\mathrm{e}}=2, p<.05\right]$.

Essentially, the same pattern of results was obtained in the analysis of the three matched subsets. Lexicalized compounds ( $541 \mathrm{msec}$ ) were named faster than were novel compounds $(574 \mathrm{msec})$. The difference was significant $\left[F_{\mathrm{s}}(1,19)=74.62, M S_{\mathrm{e}}=152, p<.001 ; F_{\mathrm{i}}(1,62)=\right.$ $\left.20.15, M S_{\mathrm{e}}=860, p<.001\right]$. Mean latencies for $\mathrm{HI}$ compounds ( $573 \mathrm{msec}$ ) and LI compounds ( $575 \mathrm{msec})$ did not differ $(F<1)$. Correlations between mean latencies and rating scores were -.06 and -.01 for Rating Studies 1 and 2 , respectively (both $p s>.5$ ).

The analysis of the errors showed a significant effect of lexicality $\left[F_{\mathrm{s}}(1,19)=16.81, M S_{\mathrm{e}}=1, p<.001\right.$; $\left.F_{\mathrm{i}}(1,62)=10.09, M S_{\mathrm{e}}=1, p<.01\right]$. More errors were made for novel compounds $(5.0 \%)$ than for lexicalized compounds $(0.9 \%)$. The difference between the error percentages for HI compounds (3.1\%) and LI compounds $(6.9 \%)$ was significant in the subject analysis $\left[F_{\mathrm{s}}(1,19)\right.$ $\left.=5.10, M S_{\mathrm{e}}=1, p<.05\right]$.

\section{Discussion}

As pointed out above, a processing strategy in which pronunciation would be based on an initial access of only the first noun predicts no difference between the lexicalized and novel compounds. The significant difference between these two categories of compounds in both analyses indicates that both nouns were accessed prior to the onset of pronunciation. A straightforward explanation of the difference between lexicalized and novel compounds involves access of orthographic representations. Lexicalized compounds are pronounced faster because ortho- 
graphic representations for these items can be accessed as single units (Butterworth, 1983; Monsell, 1985).

It may be argued, however, that this result would also have been obtained if, for some reason, left members of lexicalized compounds were more easily pronounced than left members of novel compounds. To check the validity of this alternative account, we conducted a control experiment in which the same stimuli were used. Left and right members of compounds were separated by two spaces and the subjects were instructed to pronounce only the left member.

In this control experiment, no differences between matched lexicalized and novel compounds were observed $(F<1)$. Neither was there a significant difference between the first members of matched $\mathrm{HI}$ compounds $(501 \mathrm{msec})$ and LI compounds ( $497 \mathrm{msec} ; F<1$ ). The correlations between mean latencies and mean rating scores in Rating Studies 1 and 2 was also nonsignificant $(r s=.06$ and .11 , respectively). Percentages of errors were not significantly different for different types of compounds.

In contrast to the lexical decision task, response latencies for $\mathrm{HI}$ and LI compounds did not differ significantly. It may therefore be assumed that uncontrolled lexical variables did not underlie the interference effect observed in Experiment 1. Moreover, this result supports our claim that the interference effect is due to postlexical interpretative processing of novel compounds rather than to a prelexical priming effect based on semantic relations between constituent nouns.

\section{EXPERIMENT 3}

In Experiment 1, differences were found between $\mathrm{HI}$ and LI compounds that point to an automatic interpretation of novel compounds. It can be argued, however, that the stimulus materials of Experiment 1 fostered a strategic use of semantic interpretation, because this information will speed up decisions for the lexicalized and LI compounds, which together constitute the majority of the stimuli. Strategic control of interpretative processing may be demonstrated by influencing subject expectations for novel compounds. When only a small proportion of the stimuli consists of novel compounds, no clear advantage results from using semantic information. When interpretation is under strategic control, no effects of interpretability should be found under these conditions. In the present lexical decision experiment, stimulus materials consisted mostly of morphologically simple stimuli. Orthographically legal pseudowords were used as nonwords. A small set of compounds was included in both the word and the nonword stimuli. The nonword compounds consisted of HI and LI compounds. It was assumed that this composition of the set of the stimulus materials would obliterate any strategic advantages connected with the interpretation of novel compounds.

\section{Method}

Stimulus materials consisted of 150 words and 150 nonwords. Of the 150 word stimuli, 120 were morphologically simple words and 30 were lexicalized compounds from Experiment 1 . In the set of 150 nonwords, 30 novel compounds ( $15 \mathrm{HI}$ compounds and 15 LI compounds) from Experiment 1 were included. The remaining 120 nonwords did not contain any suffixes. Both groups of novel compounds were matched with the lexicalized compounds for mean number of letters (8.6).

Stimuli were presented randomly in five blocks of 60 stimuli each. Prior to the test materials, 30 practice items were presented. All the other experimental procedures were the same as in Experiment 1. Instructions made no reference to the inclusion of compound words in the stimulus materials.

Twenty-two subjects were tested and were paid for their participation. None of them had been a subject in either of the other experiments.

\section{Results}

Mean response latencies and error percentages are presented in Table 3. Mean latencies were longer for the HI compounds $(893 \mathrm{msec})$ than for the LI compounds $(783 \mathrm{msec})$. The difference was significant in both the subject analysis $\left[F_{\mathrm{s}}(1,21)=6.22, M S_{\mathrm{e}}=8,032, p<.05\right]$ and the item analysis $\left[F_{\mathrm{i}}(1,28)=8.68, M S_{\mathrm{e}}=10,392\right.$, $p<.01]$. Mean percentage of errors was higher for $\mathrm{HI}$ compounds $(57.0 \%)$ than for LI compounds $(11.5 \%)$. The difference was highly significant $\left[F_{\mathrm{s}}(1,21)=122.54, M S_{\mathrm{e}}\right.$ $\left.=4, p<.001 ; F_{\mathrm{i}}(1,28)=42.04, M S_{\mathrm{e}}=18, p<.001\right]$. Correlations between latencies and rating scores for the novel compounds were .48 and .40 for Rating Studies 1 and 2 , respectively (both $p s<.05$ ).

To compare the results obtained in Experiment 3 with those obtained in Experiment 1, mean latencies and error percentages were calculated for the items in Experiment 1 that were also used in Experiment 3 (see Table 3). The analysis of variance for the combined results of the two experiments showed no significant effect for experiment $\left[F_{\mathrm{s}}(1,42)=2.98, M S_{\mathrm{e}}=24,862, p<.10 ; F_{\mathrm{i}}(1,28)\right.$ $\left.=3.03, M S_{\mathrm{e}}=5,951, p<.10\right]$. The effect of interpretability of the novel compounds was significant $\left[F_{s}(1,42)\right.$ $=23.41, M S_{\mathrm{e}}=5,057, p<.001 ; F_{\mathrm{i}}(1,28)=14.10$, $\left.M S_{e}=9,577, p<.01\right]$, but the interaction between experiment and interpretability was not significant $(F<1)$.

Analyses of error percentages for novel compounds in both experiments showed significant main effects for experiment $\left[F_{\mathrm{s}}(1,42)=28.13, M S_{\mathrm{e}}=7, p<.001\right.$; $\left.F_{\mathrm{i}}(1,28)=24.32, M S_{\mathrm{e}}=12, p<.001\right]$ and interpretability $\left[F_{\mathrm{s}}(1,42)=196.37, M S_{\mathrm{e}}=3, p<.001 ; F_{\mathrm{i}}(1,28)\right.$ $\left.=74.79, M S_{\mathrm{e}}=12, p<.001\right]$. The interaction was also significant $\left[F_{\mathrm{s}}(1,42)=16.87, M S_{\mathrm{e}}=3, p<.001\right.$; $\left.F_{\mathrm{i}}(1,28)=6.65, M S_{\mathrm{e}}=12, p<.05\right]$.

Table 3

Mean Latencies (in Milliseconds) and Percentages of Errors for HI and LI Compounds in Experiment 3

\begin{tabular}{lccccc}
\hline & \multicolumn{2}{c}{ Experiment 1 } & & \multicolumn{2}{c}{ Experiment 3 } \\
\cline { 2 - 3 } \cline { 5 - 6 } Nonwords & $\begin{array}{c}\text { Mean } \\
\text { Latency }\end{array}$ & $\begin{array}{c}\text { Percentage } \\
\text { of Errors }\end{array}$ & & $\begin{array}{c}\text { Mean } \\
\text { Latency }\end{array}$ & $\begin{array}{c}\text { Percentage } \\
\text { of Errors }\end{array}$ \\
\hline HI Compounds & 913 & 27.0 & & 893 & 57.0 \\
LI Compounds & 833 & 2.1 & & 783 & 11.5 \\
\hline
\end{tabular}

Note-Listed mean latencies and percentages of error for Experiment 1 involve the same items as for Experiment 3. 


\section{Discussion}

The composition of the stimulus materials made it very unlikely that the subjects would develop special strategies to deal with the interpretability of novel compounds. Most of the stimuli were morphologically simple in order to discourage decomposition into constituent morphemes (Rubin, Becker, \& Freeman, 1979; Taft, 1985). In addition, most word-nonword decisions could be based on orthographic aspects of the stimuli, making semantic considerations irrelevant for the lexical decision. Despite these changes in the stimulus materials, the main results of Experiment 3 are a replication of the results of Experiment 1 , in which significant differences between $\mathrm{HI}$ and LI compounds were obtained. The analyses of latencies for items that were presented in both experiments did not show significant differences between the two experiments. Also, effects of interpretability of novel compounds were not significantly different in the two experiments.

The analysis of error percentages for both experiments showed that more errors were made in Experiment 3 than in Experiment 1. These differences in error percentages are related to different characteristics of the set of nonwords in both experiments. The result indicates that, in Experiment 3, orthographic aspects of the stimuli played a more prominent role in decision processes. In spite of this, the semantically based interference effect for novel compounds was still obtained. The results therefore support the conclusion that interpretative processing of novel compounds in the lexical decision task is beyond strategic control of the subject.

\section{EXPERIMENT 4}

The use of the lexical decision task for studying the interpretation of novel compounds may seem to have two drawbacks. One is that the task does not provide insights in the actual interpretations assigned by the subjects to the novel compounds. Uncertainty about these interpre tations would seem to be an unavoidable consequence of the on-line measurement of interpretation processes, but it should be noted that similar uncertainty about assigned interpretations is connected with other types of semantic materials (e.g., metaphors). In their study about metaphoric processing, Glucksberg, Gildea, and Bookin (1982) asked their subjects to judge sentences for literal truth. Some sentences (e.g., "Some jobs are jails.") that were literally untrue produced a metaphoric interference effect, consisting in a lengthening of the verification times. The metaphoric truth expressed in these sentences interfered with judgments of literal truth. In the Glucksberg et al. study, it remained unclear how subjects actually comprehended the metaphorical sentences. Different subjects may have constructed different underlying grounds for the same metaphor. Similarly, in our experiments different subjects may have interpreted the same novel compound in different ways.

The second drawback has to do with the extent of the semantic interpretation. When lexical decisions were made, some kind of relatedness between the nouns may have been noticed but no particular interpretation may have been assigned to the novel compound at that time. Semantic representations for the nouns may have become available and integration processes have been initiated while the lexicon was still being searched for a representation of the novel compound. Consultation of the lexicon may stop and lexical decisions may be made while at the same time interpretation processes have proceeded far enough to cause interference without having resulted in an assigned meaning for the compound. Experiment 4 was conducted to obtain indications about the extent of semantic interpretation.

There is no obvious procedure available for measuring the extent of semantic interpretation of novel compounds, but a comparison between priming effects for members of established semantic categories and members of novel compounds may provide a reasonable indication. In Experiment 4 , we used a lexical decision task in a standard priming paradigm. Related and unrelated prime-target pairs involving members of semantic categories were included in the stimulus materials, as were pairs of nouns that had been constituents of $\mathrm{HI}$ compounds in Experiments 1-3.

Priming effects for members of semantic categories that are not related associatively have been found in a lexical decision but not in a naming task (Lupker, 1984), indicating that priming effects for these materials are to be located postlexically. For novel compounds, the combined results of Experiments 1 and 2 suggest that differences in interpretability between compounds also arise postlexically. For both types of stimulus materials, semantic processing subsequent to lexical access apparently affects the lexical decision. When prime and target are related, there will be a bias to decide that the target is a word, and "yes" responses will be facilitated. For members of established semantic categories, relatedness will be based on the similarity of the semantic representations. Assessment of this similarity requires at least processing of important or salient aspects of the semantic representations of the members. For members of novel compounds, semantic representations of the constituent nouns will have to be processed in considerable depth to determine how the semantic interpretation of the first noun fits into the semantic representation of the second noun. When this integration succeeds, relatedness between the nouns, as mediated by the interpretation of their combination, may be as strong as between members of established categories. Thus, extensive interpretation of novel compounds suggests that priming effects for members of established categories and for members of novel compounds may be of comparable magnitude. Relatedness between prime and target may create for both types of materials an equal bias to decide that the target is a word.

\section{Method}

Stimulus materials. Prime-target word stimuli were divided into four classes of 30 items each. One class was constituted by related items and consisted of frequent members of different semantic 
Table 4

Sample of Word Pairs used in Experiment 4

\begin{tabular}{|c|c|}
\hline \multicolumn{2}{|c|}{ Relatedness } \\
\hline Related & Unrelated \\
\hline \multicolumn{2}{|c|}{ Category Pairs } \\
\hline $\begin{array}{l}\text { muis-zebra (mouse-zebra) } \\
\text { neus-voet (nose-foot) }\end{array}$ & $\begin{array}{l}\text { mond-zebra (mouth-zebra) } \\
\text { hond-voet (dog-foot) }\end{array}$ \\
\hline \multicolumn{2}{|c|}{ Compound Pairs } \\
\hline $\begin{array}{l}\text { herberg-kok (hostelry-cook) } \\
\text { citroen-markt (lemon-market) }\end{array}$ & $\begin{array}{l}\text { gordijn-kok (curtain-cook) } \\
\text { baard-markt (beard-market) }\end{array}$ \\
\hline
\end{tabular}

Note-Pairs in parentheses are the English translations of the Dutch pairs.

categories (Hudson, 1982). Six pairs from five categories (animals, metals, body parts, pieces of clothing, and vehicles) were used. Items in related pairs were semantically, but not associatively, related (De Groot, 1980). The second class contained unrelated pairs consisting of random pairings of category members of different categories used in the first class. The third class consisted of prime-target combinations that together had constituted HI compounds used in Experiment 1. First nouns functioned as primes and second members as targets. Primes and targets were not associatively related (De Groot, 1980). The fourth class consisted of random, unrelated pairings of the first and second members of the HI compounds. Examples of all four classes of word pairs are presented in Table 4.

Nonword targets were regular pseudowords according to Dutch orthography. They were constructed by changing one or two letters of randomly selected nouns. For half of the 120 nonword stimuli, primes were infrequent members of the semantic categories used for the word stimuli. For the other half, the primes were randomly selected nouns that were similar to the primes for the compound stimuli.

Word stimuli were divided into two lists. A particular target was paired with a related prime in one list and paired with an unrelated prime in the other list. This arrangement was applied for the category pairs and the compound pairs separately. Thus, each subject was presented half of the word stimuli and saw each target only once. Nonword stimuli were the same for all subjects.

Procedure and Subjects. General experimental conditions were the same as in Experiments 1 and 2. Each trial started with a 1-sec presentation of an asterisk. Immediately thereafter, the prime was presented for $500 \mathrm{msec}$. After a blank screen for $40 \mathrm{msec}$, the target was displayed one line under the prime. The target remained on the screen for a maximum of $1,500 \mathrm{msec}$ or until the subject responded. Intertrial intervals were $3 \mathrm{sec}$. Prior to the presentation of the 120 experimental items, the subjects were given 34 practice trials. Subsequent to errors made by the subjects, filler items were introduced in the stimulus materials.

Thirty subjects drawn from the subject pool of the IWTS were run. Fifteen subjects were randomly assigned to each of the two lists. None of the subjects had participated in any of the previous experiments.

\section{Results}

Mean latencies and percentages of errors for different experimental conditions are presented in Table 5. Semantic category stimuli were responded to faster than were compound stimuli $\left[F_{\mathrm{s}}(1,29)=76.39, M S_{\mathrm{e}}=373, p<\right.$ $\left.001 ; F_{\mathrm{i}}(1,58)=6.99, M S_{\mathrm{e}}=5,517, p<.05\right]$. Latencies for related pairs were shorter than for unrelated pairs $\left[F_{\mathrm{s}}(1,29)=8.36, M S_{\mathrm{e}}=884, p<.01 ; F_{\mathrm{i}}(1,58)=\right.$ $\left.18.35, M S_{\mathrm{e}}=633, p<.001\right]$. The interaction between type of category and relatedness was not significant.
The error analysis showed a significant effect for type of category in the subject analysis $\left[F_{\mathrm{s}}(1,29)=33.19, M S_{\mathrm{e}}\right.$ $=.4, p<.001]$. More errors were made for the compound stimuli than for semantic category stimuli. Differences between related and unrelated conditions were also significant $\left[F_{\mathrm{s}}(1,29)=9.10, M S_{\mathrm{c}}=1, p<.01 ; F_{\mathrm{i}}(1,58)\right.$ $\left.=8.81, M S_{\mathrm{c}}=1, p<.01\right]$. More errors were made in the unrelated conditions. The interaction between type of category and relatedness was not significant.

A separate analysis for the semantic category targets showed a relatedness effect of $23 \mathrm{msec}\left[F_{\mathrm{s}}(1,29)=5.35\right.$, $M S_{\mathrm{e}}=1,249, p<.05 ; F_{\mathrm{i}}(1,29)=13.18, M S_{\mathrm{e}}=635$, $p<.01]$. More errors were made for unrelated items than for related items $\left[F_{\mathrm{s}}(1,29)=9.72, M S_{\mathrm{e}}=.4, p<.01\right.$; $\left.F_{\mathrm{i}}(1,29)=4.63, M S_{\mathrm{e}}=1, p<.05\right]$.

For the compound targets, a significant relatedness effect of $16 \mathrm{msec}$ was observed $\left[F_{\mathrm{s}}(1,29)=4.64, M S_{\mathrm{e}}=\right.$ $\left.343, p<.05 ; F_{\mathrm{i}}(1,29)=5.88, M S_{\mathrm{c}}=631, p<.05\right]$. Significantly more errors were made for the unrelated targets $\left[F_{\mathrm{s}}(1,29)=4.66, M S_{\mathrm{e}}=1, p<.05 ; F_{\mathrm{i}}(1,29)=\right.$ 4.31, $\left.M S_{\mathrm{e}}=1, p<.05\right]$.

\section{Discussion}

As was argued above, semantic relatedness between prime and target will result in a bias for related pairs to decide that the target is a word. The strength of this bias will vary with the relatedness between prime and target. When prime and target are weakly related, small or insignificant priming effects will be observed. When prime and target are strongly related, priming effects will increase. We used priming effects between members of established categories as a measure to assess the relatedness between the nouns of $\mathrm{HI}$ compounds as mediated by the interpretation of the combination. Priming effects were not significantly different for members of established categories and members of novel compounds. This result suggests that interpretative processing for novel compounds is not limited to a mere global assessment of semantic relatedness. Rather superficial processing would have led to much smaller priming effects for members of novel compounds. Equal priming effects therefore indicate that the nouns were integrated in a meaningful interpretation. The relatedness between the constituent nouns arises exactly because this interpretation has been achieved. As was pointed out in the introduction, many novel compounds are inherently ambiguous because the two nouns can be related in different ways. The equal priming ef-

Table 5

Mean Latencies (in Milliseconds) and Percentages of Errors for Related and Unrelated Targets in Semantic Category Pairs and Compound Pairs in Experiment 4

\begin{tabular}{|c|c|c|c|c|}
\hline \multirow[b]{3}{*}{$\begin{array}{l}\text { Type of } \\
\text { Stimulus }\end{array}$} & \multicolumn{4}{|c|}{ Relatedness } \\
\hline & \multicolumn{2}{|c|}{ Related } & \multicolumn{2}{|c|}{ Unrelated } \\
\hline & $\begin{array}{c}\text { Mean } \\
\text { Latency }\end{array}$ & $\begin{array}{c}\text { Percentage } \\
\text { of Errors }\end{array}$ & $\begin{array}{c}\text { Mean } \\
\text { Latency }\end{array}$ & $\begin{array}{l}\text { Percentage } \\
\text { of Errors }\end{array}$ \\
\hline Semantic Categ & 500 & 1.1 & 523 & 5.6 \\
\hline Compounds & 539 & 5.8 & 555 & 10.7 \\
\hline
\end{tabular}


fects obtained in Experiment 4 are clear testimony of how fast and efficient the integration process is.

\section{GENERAL DISCUSSION}

Our experiments dealt with the interpretative processing of novel compounds in a lexical decision task, whose performance does not require interpretation. The results of our experiments show that interpretations for novel compounds are created on the basis of the meaning of constituent nouns without any contextual support and without any deliberate effort at interpretation by the subject. In the lexical decision task in Experiment 1, significant differences were found between $\mathrm{HI}$ and LI compounds that functioned as nonwords. Interpretative processes were shown to be insensitive to strategic control by the subject, because differences between HI and LI compounds were also found when the stimulus materials included only a small number of interpretable compounds (Experiment 3). This result indicates that a likely meaning for a novel compound may become available automatically without requiring conscious attempts at interpretation by the subject. Experiment 4 demonstrated that interpretative processing was rather extensive and certainly went beyond a mere global assessment of semantic relatedness between the nouns.

Before discussing the implications of our results for theories about the interpretation of novel compounds in more detail, we should point out that our results are also relevant for issues having to do with access of morphologically complex words. Several models (e.g., Butterworth, 1983; Schreuder, 1990; Taft, 1985) have been proposed to account for the access of these words. The augmented access model, developed by Caramazza, Laudanna, and Romani (1988) on the basis of experimental results with inflected words, would seem rather successful in accounting for our results. In this model, morphological complex words are assumed to cause activation of whole-word representations and activation of constituent morphemes. The faster recognition of lexicalized compounds is explained by the model's assumption that access to whole-word representations usually proceeds faster than does access to constituent morphemes. Central to the model is the distinction between two levels of processing in lexical access. At one level, access representations are specified; at the other level, lexical/linguistic information is represented. Information relevant for the combinability of morphemes becomes available with lexical/linguistic information. The experiments of Caramazza et al. involved inflections only. Significant differences were found between nonwords that were morphologically legal or illegal. Illegal nonwords can be rejected at the first level, the level at which access representations are made available. The rejection of legal nonwords requires processing at the second level, where it is determined that the legal combination does not constitute a word. Applying the model to novel compounds, it will be clear that the rejection of legal combinations of nouns in the lexical decision task engages the second level of processing. As Caramazza et al. note, the information needed to determine legal combinability is rather complex and will include orthographic, morphological, and syntactic aspects. Our results show that semantic information will also have to be added.

Our results are of special interest for methodological issues in the study of novel compounds. Rating results showed judgments of interpretability to be reliable and to be virtually independent of composition of the set of stimulus materials. Taken together, our results with online interpretation provide clear evidence that the lexical decision task provides a sensitive measure for interpretative processing of novel compounds in isolation. In the introduction, we have argued that a task that does not require interpretation will have certain advantages over semantic tasks, such as speeded judgments for meaningfulness. In semantic tasks, decision processes may be more complicated due to additional considerations that are only indirectly related to the actual interpretation process. Discrepancies between lexical decision times and reaction times obtained in speeded semantic classification tasks support this suggestion. In an experiment in which subjects had to classify adjective-noun and noun-noun combinations for meaningfulness, Murphy (1990, Experiment 1) obtained mean latencies that were about twice as long $(1,857 \mathrm{msec}$ for noun-noun combinations) as the latencies we obtained in the lexical decision task. Using the same task with our materials, we obtained latencies of about $1,100 \mathrm{msec}$ for $\mathrm{HI}$ compounds. Our results indicate that the basic interpretation of novel compounds may be completed much faster than one is led to believe on the basis of results in semantic tasks.

Theoretically more interesting are the kind of processes that allow such a fast and efficient interpretation of isolated novel compounds. Obviously, these processes are related to systematic differences between $\mathrm{HI}$ and LI compounds. We performed two post hoc analyses that reveal different characteristics of the two types of compounds.

One analysis had to do with aspects of semantic relations between the two nouns. Several authors (Levi, 1978; $\mathrm{Li}, 1971$ ) have noted that a limited number of basic semantic relations seem to underlie the interpretation of the majority of novel compounds. Two predictions can be formulated. It may be expected that in paraphrases of the meanings of particular HI compounds fewer of these basic relations will be found, indicating greater agreement between subjects in the interpretation of these items. For both $\mathrm{HI}$ and $\mathrm{LI}$ compounds, paraphrases are also to be expected that do not express one of these basic semantic relations. The proportion of such idiosyncratic interpretations may be expected to be significantly larger for LI compounds.

To test these hypotheses, we used a paraphrasing task. Twenty-eight novel compounds that had been used in the on-line experiments were randomly selected and presented to 20 subjects. Fourteen of these compounds were HI compounds; the other 14 were LI compounds. The subjects were instructed to say out loud the first interpreta- 
tion that came to mind. The experimenter wrote down the subjects' paraphrases. The written-out paraphrases were classified by three independent judges. For this classification, a taxonomy of relations was adopted from Levi (1978). A scoring form was used on which 10 categories (ABOUT [court tragedy], BE [slum building], CAUSE [thorn wound], FOR [donkey cot], FROM [melon pulp], HAVE [wrinkled countenance], IN [beard louse], MAKE [frog song], USE [lumber bag], and RESIDUAL) were entered. Each judge assigned each paraphrase to one of these categories. It should be noted that we did not intend this classification schema to be an exhaustive description of all novel compounds (cf. Downing, 1977).

Agreement between judges was calculated as the percentage of identical classifications. Percentages of agreement for different combinations of the three judges were $58.4,68.8$, and 60.9. To calculate differences between $\mathrm{HI}$ and $\mathrm{LI}$ compounds in diverseness of interpretation, we devised a skewness measure based on the sum of the cumulative frequencies of the scoring categories ordered by frequency. Maximal uniformity of classification results when all 20 paraphrases of each compound are assigned to the same category by each judge. This maximal cumulative frequency was set to 1.0. Minimal uniformity (set equal to 0.0 ) results when the 20 paraphrases are equally divided among the 10 categories. Thus, the skewness measure converted the sum of the cumulative frequencies for every compound by each of the judges into a value between 1.0 and 0.0 .

The analysis of variance on the skewness measures showed a significant effect for type of compound $[F(1,78)$ $\left.=41.62, M S_{\mathrm{e}}=299, p<.001\right]$. Mean scores were higher for the HI compounds (.59) than for the LI compounds (.32). Differences in diverseness of interpretation may also be expected to show in the frequencies of the residual category. More extensive use was made of this category for the LI compound $(\mathbf{2 3 . 8 \%})$ than for the HI compounds $(8.9 \%)$. These results confirm the expected greater diversity in interpretation for the LI compounds.

The results of the paraphrasing task indicate that differences in interpretability can (partly) be attributed to the appropriateness of a set of basic underlying semantic relations. For the interpretative processing of novel compounds, this suggests that fast and efficient interpretation may be achieved by considering a small stock of frequent semantic relations to relate the nouns in the compounds. More complicated interpretation processes will ensue when none of these basic relations leads to a meaningful interpretation.

The second post hoc analysis of characteristics of $\mathrm{HI}$ and LI compounds suggests an additional underlying mechanism for the selection of an appropriate relation between the nouns. We determined for all novel compounds the number of lexicalized compounds with the same first or second member, using the CELEX database (Burnage, 1990) that contained virtually all lexicalized Dutch compounds. Informal inspection of these data showed that the interpretability of isolated novel compounds may be de- termined by the availability of lexicalized compounds that can serve as a model for the interpretation. A representative example from our data is provided by the pair baardluis (beard louse [HI compound]) and wimpelvlo (banner flea [LI compound]). Both these compounds would seem to be interpretable by invoking an IN relation. The difference in interpretability may be explained by the fact that there are lexicalized compounds in Dutch that contain the same words or semantically related words (like baardschimmel [beard eczema] or hoofdluis [head louse]) and that contain the same relation as beard louse. There exists only one lexicalized Dutch compound (watervlo [water flea]) that contains the word vlo (flea), in which the other member, moreover, is not related to banner. In experiments currently in progress in our laboratory, we are investigating the role of lexicalized compounds in the interpretation of novel compounds in more detail and have found that the number of lexicalized compounds contributes to the interference effect in lexical decision tasks. Thus, the high interpretability of particular compounds may be due to the availability of familiar lexicalized compounds with semantically related nouns. Relations within these lexicalized compounds may be among the first ones that are considered in the interpretation process; when these relations hold, interpretation of the novel compound will be fast and effortless.

Relating our results to recent research concerned with conceptual combinations, it should be noted that a very small portion of this research has been concerned directly with noun-noun compounds. In adjective-noun combinations (Medin \& Shoben, 1988; Smith, Osherson, Rips, $\&$ Keane, 1988), as in conjunctive and disjunctive concepts (Hampton, 1987, 1988), different combinatorial processes may be engaged. We believe that our results are also relevant for research of these combinations in that they may offer a promising methodological approach to the experimental study of these combinations.

The recent study of Murphy (1990) is concerned with interpretative processing of noun-noun concepts and can be related to central concerns of our experiments. We have already pointed to important methodological differences between Murphy's experiments and ours. Divergences may also be discerned at a more theoretical level. To account for the interpretation of novel compounds, Murphy (1988; Cohen \& Murphy, 1984) proposes the concept specialization model. According to this model, the head (second) noun of the compound can be represented as a schema. Slots in these schemata can be filled by first nouns, which provide a specialization of the concept expressed by the head noun. On the basis of our post hoc analyses of differences between $\mathrm{HI}$ and LI compounds, we believe that interpretation involves selection from a small set of frequent semantic relations, perhaps guided by the analogy of lexicalized compounds with the same nouns as the novel compounds. While both approaches need elaboration in specifying exactly how a particular slot or relation is selected, they seem to differ in the role assigned to world knowledge. According to Murphy's model, un- 
derstanding novel compounds is a heavily knowledgedependent process. Our results suggest that understanding is based primarily on important aspects of the semantic representations of the nouns involved.

This brings us back to the problem we started out with: the contribution of the context to the interpretation of compounds. Undoubtedly, a comprehensive theory about the interpretation of novel compounds will ultimately have to account for the effects of context. Because hardly anything is known about interpretation processes for novel compounds, it seems advisable to concentrate initially on the interpretability of compounds in isolation. An account of the various ways in which context might affect interpretative processes will, in any case, have to incorporate a component in which the contribution of the semantic representation of the nouns is specified. The results of our experiments show that the lexical decision task may be a suitable instrument for the investigation of that component.

\section{REFERENCES}

Barsalou, L. W. (1983). Ad hoc categories. Memory \& Cognition, 11, 211-227.

Bonse-Beier, J. (1987). Poetic compounds (pp. 37-84). Tubingen: Max Niemeyer Verlag.

Burnage, G. (1990). CELEX, A guide for users. Nijmegen: CELEX, University of Nijmegen.

ButTERWORTH, B. (1983). Lexical representation. In B. Butterworth (Ed.), Language production. Vol. II: Development, writing and other language processes (pp. 257-294). London: Academic Press.

Caramazza, A., Laudanna, A., Romani, C. (1988). Lexical access and inflectional morphology. Cognition, 28, 297-332.

Chumbley, J. I., Balota, D. A. (1984). A word's meaning affects the decision in lexical decision. Memory \& Cognition, 12, 590-606.

Clark, E. V., Berman, R. A. (1987). Types of linguistic knowledge: Interpreting and producing compound nouns. Joumal of Child Language, 14, 547-567.

Clark, E. V., ClaRk, H. H. (1979). When nouns surface as verbs. Language, 55, 767-811.

Cohen, B., \& Murphy, G. L. (1984). Models of concepts. Cognitive Science, 8, 27-58.

Coulmas, F. (1987). New words, complexity and arbitrariness. In T. T. Ballmer \& W. Wildgen (Eds.), Process linguistics (pp. 227-251). Tubingen: Max Niemeyer Verlag.

DE Groot, A. M. B. (1980). Mondelinge woord associatie normen. Lisse: Swets en Zeitlinger.

Downing, P. (1977). On the creation and use of English compound nouns. Language, 53, 810-842.

Forster, K. I. (1976). Accessing the mental lexicon. In R. J. Wales \& E. Walker (Eds.), New approaches to language mechanisms (pp. 257-287). Amsterdam: North-Holland.

FORSTER, K. I. (1979). Levels of processing and the structure of the language processor. In W. E. Cooper \& E. C. T. Walker (Eds.), Sentence processing (pp. 27-85). Hillsdale, NJ: Erlbaum.

Geer, S. E., Gleitman, H., \&leitman, L. (1972). Paraphrasing and remembering compound words. Journal of Verbal Learning \& Verbal Behavior, 11, 348-355.

Gerrig, R. J. (1986). Process and products of lexical access. Language \& Cognitive Processes, 1, 187-195.

GerRIG, R. J. (1989). The time course of sense creation. Memory \& Cognition, 17, 194-207.

Gleitman, L. R., Gleitman, H. (1970). Phrase and paraphrase: Some innovative uses of language. New York: Norton.

Glucksberg, S., GiLDEA, P., B BookIN, H. B. (1982). On understanding nonliteral speech: Can people ignore metaphors? Journal of Verbal Learning \& Verbal Behavior, 21, 85-98.
Hampton, J. A. (1987). Inheritance of attributes in natural concept conjunctions. Memory \& Cognition, 15, 55-71.

HAMPTON, J. A. (1988). Overextension of conjunctive concepts: Evidence for a unitary model of concept typicality and class inclusion. Journal of Experimental Psychology: Leaming, Memory, \& Cognition, 14, 12-32.

HENDERSON, L. (1982). Othography and word recognition in reading. London: Academic Press.

HUDSON, P. T. W. (1982). Preliminary category norms for verbal items in 52 categories in Dutch (Internal Rep.). Nijmegen: University of Nijmegen, Vakgroep Psychologische Funktieleer.

JAMES. C. T. (1975). The role of semantic information in lexical decisions. Journal of Experimental Psychology: Human Perception \& Performance, 1, 130-136.

JASTRZEMBSKI, J. E. (1981). Multiple meanings, number of related meanings, frequency of occurrence, and the lexicon. Cognitive Psychology, 13, 278-305

LEVI, J. N. (1978). The syntax and semantics of complex nominals. London: Academic Press

Li, C. (1971). Semantics and the structure of compounds in Chinese. Unpublished doctoral dissertation, University of California, Berkeley.

LUPKER, S. J. (1984). Semantic priming without association: A second look. Journal of Verbal Learning \& Verbal Behavior, 23, 709-733.

Medin, D. L., Shoben, E. J. (1988). Context and structure in conceptual combination. Cognitive Psychology, 20, 158-190.

Monsell, S. (1985). Repetition and the lexicon. In A. Ellis (Ed.), Progress in the psychology of language (Vol. 2, pp. 147-195). Hillsdale, NJ: Erlbaum.

MURPhy, G. L. (1988). Comprehending complex concepts. Cognitive Science, 12, 529-562.

MURPHY, G. L. (1990). Noun phrase interpretation and conceptual combination. Journal of Memory \& Language, 29, 259-288.

NeELY, J. H. (1991). Semantic priming effects in visual word recognition: A selective review of current findings and theories. In D. Besner \& G. W. Humphreys (Eds.), Basic processes in reading: Visual word recognition (pp. 264-336). Hillsdale, NJ: Erlbaum.

Rubin, G. S., Becker, C. A., \& Feeman, R. H. (1979). Morphological structure and its effect on visual word recognition. Journal of Verbal Learning \& Verbal Behavior, 18, 757-767.

SChreuder, R. (1990). Lexical processing of verbs with separable particles. In G. E. Booy \& J, van Marle (Eds.), Yearbook of morphology (Vol. 3, pp. 65-79). Amsterdam: Foris.

Schreuder, R., Flores d'Arcais, G. B. . Glazenborg, G. (1984). Effects of perceptual and conceptual similarity in semantic priming. Psychological Research, 45, 339-354

Seidengerg, M. S., Waters, G. S., Sanders, M., \& Langer, P. (1984). Pre- and postlexical loci of contextual effects on word recognition. Memory \& Cognition, 12, 315-328.

SELKIRK, E. O (1982). The syntax of words. Cambridge, MA: MIT Press.

Smith, E. E., Osherson, D. N., Rips, L. J., Keane, M. (1988). Combining prototypes: A selective modification model. Cognitive Science, 12, 485-527.

TAFT, M. (1985). The decoding of words in lexical access: A review of the morphographic approach. In D. Besner, T. G. Waller, \& G. E. MacKinnon (Eds.), Reading research: Advances in theory and practice (Vol. 5, pp. 83-123). London: Academic Press.

TAFT, M., Forster, K. I. (1976). Lexical storage and retrieval of polymorphemic and polysyllabic words. Joumal of Verbal Learning \& Verbal Behavior, 15, 607-620.

UIT DEN BOOGAART, P. C. (1975). Woordfrequenties in geschreven en gesproken Nederlands (Word frequencies in written and spoken Dutch). Utrecht: Oosthoek, Scheltema, \& Holkema.

VAN DALE (1984). Groot Woordenboek der Nederlandse Taal. Utrecht Antwerpen: Van Dale Lexicografie.

VAN JaArsveld, H. J., Rattink, G. E. (1988). Frequency effects in the processing of lexicalized and novel nominal compounds. Journal of Psycholinguistic Research, 17, 447-473.

WHALEY, C. P. (1978). Word-nonword classification time. Journal of Verbal Learning \& Verbal Behavior, 17, 143-154 


\section{NOTES}

1. For the sake of brevity, we use compound for the more restricted set of nominal compounds (noun-noun compounds). Research will have to show whether results obtained with this type of compound are generalizable to other types, such as adjective-noun compounds (Selkirk, 1982).

2. Unlike English novel compounds, nouns in Dutch compounds can simply be juxtaposed, unless one of the compounds is a foreign loan word. As Dutch novel and lexicalized compounds are written as one unit, their orthography does not provide a clue as to their lexical stans.
In Dutch compounds, binding morphemes like $e, e n, e r$, or $s$ occur. The occurrence of these binding morphemes may affect the acceptability of the compounds. Some compounds sound odd when the binding morpheme is left out. Phonological and morphological aspects seem to be the main factors for insertion of a binding morpheme.

3. Lexicalized compounds were all endocentric in nature. Entities denoted by endocentric compounds are a proper subset of entities denoted by their head noun (i.e., the second constituent). Examples of endocentric compounds are beehive, which is a kind of hive, and armchair, which is a kind of chair. Another, less frequent, type of compound comprises exocentric compounds, where the entity denoted is a hyponym of some unexpressed semantic head (e.g., a redskin is a person with a red skin).

\begin{abstract}
APPENDIX
Stimuli from Experiment 4

Lexicalized Compounds

atoombom (atomic bomb), berghut (mountain hut), bierkrat (beer crate), bontmuts (fur hat), briefkaart (postcard), dienstplicht (military service), fakkeltocht (torchlight procession), fruitschaal (fruit bowl), geldsom (cash sum), hartklep (heart valve), hoofdhaar (head hair), hooischuur (hay barn), kabelbaan (cable lift), kantlijn (margin line), kerkorgel (church organ), kluisdeur (safe door), kniekous (knee sock), kofferbak (trunk), korenveld (cornfield), kroegbaas (innkeeper), kruitlucht (gunpowder smell), kwarktaart (cheesecake), lintworm (tapeworm), maandblad (monthly magazine), meubelzaak (furniture shop), modderpoel (quagmire), molenwiek (windmill arm), muilkorf (muzzle), muzieknoot (musical note), nekkramp (spotted fever), plaatsnaam (place name), postzak (mailbag), psalmbundel (psalm book), raamkozijn (window frame), rietsuiker (cane sugar), roomsoes (cream puff), rotsblok (boulder), rugkwaal (backache), rumfles (rum bottle), schildklier (thyroid gland), slootwater (ditchwater), sneeuwvlok (snowflake), snoekbaars (pike perch), spoorbiels (railroad tie), staalplaat (steelplate), stemband (vocal cord), strandhoed (beach cap), tafellamp (table-lamp), tentzeil (tent cloth), torenflat (high-rise flat), treinramp (railroad disaster), tuinhuis (garden house), vaatdoek (dishcloth), veerboot (ferryboat), wagenwiel (car wheel), wereldbeker (World Cup), winkelruit (shop window), zomerjas (summer jacket)
\end{abstract}

\title{
HI Compounds
}

baardluis (beard louse), borstwrat (chest wart), bosbever (wood beaver), brugverkeer (bridge traffic), citroenmarkt (lemon market), dekenhoes (blanket cover), doornwond (thorn wound), douchekuip (shower tub), dropkleur (liquorice color), ezelhok (donkey cot), gordijnlap (curtain piece), grieptijd (flu season), herbergkok (hostelry cook), hofdrama (court tragedy), kamerhaard (chamber stove), kikkerlied (frog song), kogelgevaar (bullet danger), krotpand (slum building), kuifmode (quiff fashion), lastkameel (packcamel), meloenmoes (melon pulp), merkworst (brand sausage), negergrap (negro joke), paleiskelner (palace waiter), parfumvleug (perfume scent), plafondplug (ceiling plug), rimpelgelaat (wrinkled countenance), rommeltas (lumber bag), smaragdspeld (emerald pin), theedame (tea lady)

\section{Compounds}

beugeltrui (clamp jumper), bodemsleutel (soil key), boezemglas (bosom glass), boomzonde (tree sin), cijferverf (figure paint), eeuwtop (century top), forelzolder (trout attic), heuphoef (hip hoof), kloostervonk (monastery spark), klosklerk (chock clerk), kroonkantine (crown canteen), lakenbiet (sheet beet), mantelwoede (cloak rage), mistwimper (fog lash), museumwoud (museum forest), parkietvezel (parakeet fiber), paussoort (pope type), puntwelp (dot cub), schaarhaak (scissors hook), speenvork (nipple fork), spierkompas (muscle compass), spleetkano (crack canoe), stijlketel (style kettle), stripprei (strip leek), stropgesp (halter buckle), teenteil (toe tub), tongdoel (tongue target), velgbeuk (rim beech), wimpelvlo (banner flea), zalmsoda (salmon soda)

(Manuscript received December 23, 1989; revision accepted for publication December 19, 1990.) 